\title{
Бенчмаркинг как инструмент повышения финансовой эффективности инновационного проекта
}

\author{
Вепрева Н.С. ${ }^{30}$
}

В соответствии с тем что стратегическим приоритетом развития России объявлен переход на инновачионную экономику, значительное количество промышленных предприятий разрабатывает и реализует различные инновационные проекты. Однако из-за отсутствия систем проектного управления и опыта работы с такими проектами финансовая эффективность их незначительна. Одним из способов повышения финансовой эффективности инновачионных проектов является использование такого инструмента, как бенчмаркинг.

JEL: M21, L21

Ключевые слова: проект, риски, финансы, цели, ключевые показатели эффективности

Под бенчмаркингом в общем случае понимают сравнительную оценку результатов деятельности компании (по четырем направлениям системы сбалансированных показателей либо по показателям МСФО) с другими компаниями в рамках отрасли либо смежных отраслей. В частности, под финансовым бенчмаркингом понимают выполнение финансового анализа и сравнение результатов эффективности использования активов для определения конкурентоспособности компании (Дерески, Кристофер, 2008).

Кроме анализа результатов деятельности компания может использовать так называемые «лучшие практики», то есть применение в процессе управления компанией тех инструментов, которые успешно применяются в других компаниях.

Проблемой в данном случае является определение «доноров», то есть компаний, на примере которых можно выбирать, оценивать эффективность и транслировать на собственные бизнес-процессы инструменты управления. Однако для адекватного использования бенчмаркинга необходимо создание альянса, где компания-донор добровольно раскроет часть информации об инструментах и эффективности их использования. В данном случае удастся понять не только то, как работает сам инструмент, но и его взаимосвязь с другими функциями, а также этапы его развития и особенности применения. Это существенный аспект, который позволит не только избежать ошибок внедрения, но и сэкономить на процедурах due diligence, что позволит сократить бюджет на бенчмаркинг.

Бенчмаркинг, будучи фактически инструментом по внедрению изменений, становится мощным катализатором риска при неверном использовании. Связано это с тем, что в самолетостроении очень важным фактором является безопасность полетов, в связи с этим существуют требования законодательства, жестко регламентирующие авиастроение. Для работы на международном рынке требования к производителю компонентов российского законодательства дополняются международными. Таким образом, с одной стороны, требуется жестко соблюдать правила, с другой - крайне взвешенно подходить к изменениям, поскольку производственные ошибки могут сказаться на многом: безопасности полетов, стоимости устранения ошибки, репутации компании на мировом рынке, завоевание которого стратегически важно для страны. Именно поэтому важен каждый шаг, а первый - определяет направление. В бенчмаркинге одной из первых стадий процесса является выбор партнера

30 Ведущий преподаватель кафедры менеджмента Сибирско-Американского факультета Иркутского государственного университета, заместитель начальника отдела управления программ по международной кооперации Иркутского авиационного завода - филиала ОАО «Корпорации «Иркут». 
(см. таблицу 1).

Таблица 1

Оценка вариантов использования доноров для бенчмаркинга

\begin{tabular}{|c|c|c|c|}
\hline $\begin{array}{c}\text { Классификация } \\
\text { предприятия - } \\
\text { донора }\end{array}$ & $\begin{array}{c}\text { Доступ к } \\
\text { информации }\end{array}$ & $\begin{array}{c}\text { Метод получения } \\
\text { информации }\end{array}$ & $\begin{array}{c}\text { Необходимость } \\
\text { адаптации методов с } \\
\text { учетом специфики } \\
\text { бизнеса } \\
\end{array}$ \\
\hline Конкуренты & $\begin{array}{l}\text { Доступ к } \\
\text { информации } \\
\text { весьма } \\
\text { ограничен }\end{array}$ & $\begin{array}{l}\text { Использование открытых } \\
\text { источников информации, } \\
\text { обмен опытом в рамках } \\
\text { конференций, семинаров }\end{array}$ & $\begin{array}{ll}\text { Низкая } & \text { (если } \\
\text { бенчмаркинг } & \\
\text { проводится в } & \text { зоне, } \\
\text { выступающей } & \\
\text { объектом } & \\
\text { конкуренции) } & \\
\end{array}$ \\
\hline $\begin{array}{l}\text { Партнеры } \\
\text { (заказчики, } \\
\text { поставщики, др.) }\end{array}$ & $\begin{array}{l}\text { Доступ к } \\
\text { информации } \\
\text { возможен }\end{array}$ & $\begin{array}{l}\text { Использование открытых } \\
\text { источников информации, } \\
\text { обмен опытом в рамках } \\
\text { конференций, семинаров } \\
\text { организация практического } \\
\text { обучения } \\
\text { приглашение представителей } \\
\text { компании для проведения } \\
\text { семинаров/сессий, } \\
\text { направленных } \\
\text { практическую демонстрацию }\end{array}$ & 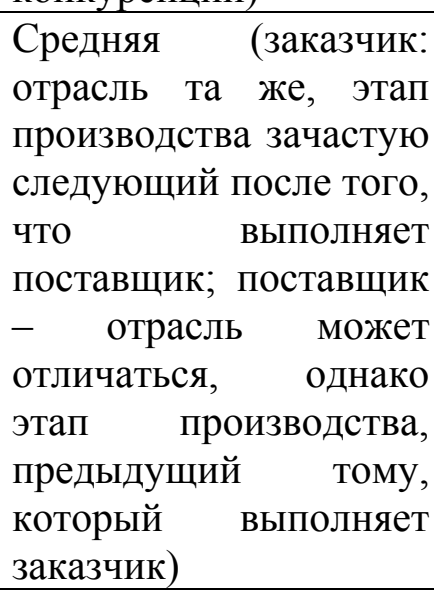 \\
\hline $\begin{array}{lr}\text { Предприятия } \\
\text { другой rферы } \\
\text { бизнеса, } \\
\text { являющиеся не } \\
\text { конкурентами, ни } \\
\text { партнерами }\end{array}$ & $\begin{array}{l}\text { Доступ к } \\
\text { информации } \\
\text { ограничен }\end{array}$ & $\begin{array}{l}\text { Использование открытых } \\
\text { источников информации, } \\
\text { обмен опытом в рамках } \\
\text { конференций, семинаров } \\
\text { организация практического } \\
\text { обучения } \\
\text { приглашение представителей } \\
\text { компании для проведения } \\
\text { семинаров/сессий, } \\
\text { направленных } \\
\text { практическую демонстрацию }\end{array}$ & $\begin{array}{lr}\text { Высокая } & \text { (необходимо } \\
\text { принимать } & \text { во } \\
\text { внимание } & \text { отличия } \\
\text { отрасли, } & \text { способы } \\
\text { организации } & \\
\text { производства и т.д.) }\end{array}$ \\
\hline
\end{tabular}

Выбор партнеров по бенчмаркингу для предприятия авиапромышленной отрасли можно начать с рассмотрения конкурентов. Их, в свою очередь, традиционно разделяют на прямых (выпускающих тот же самый продукт или очень близкий по характеристикам) и косвенных (либо потенциально способных выпускать аналогичный продукт, но более качественно и с меньшими издержками, либо уже выпускающих схожий продукт). К первой категории в российской действительности можно отнести ряд российских предприятий, выпускающих аналогичные летательные аппараты (далее - ЛА) или же отдельные компоненты для них, и также крупнейших зарубежных игроков, выпускающих аналогичные или даже опережающие по своим характеристикам ЛА и отдельные компоненты для них. И с первыми, и со вторыми возможен обмен опытом в рамках регулярно организуемых выставок и конференций.

Ко второй категории потенциальных доноров отнесем заказчиков. Это предприятия, выполняющие определенные работы с изготовленным для них продуктом и, что возможно, осуществляющие и самостоятельный выпуск такого продукта наряду со своими заказчиками. 
В этом случае очевидна возможность и применимость любой инициативы по бенчмаркингу с принятием во внимание культурного фактора, особенностей законодательства, а также объемов производства. В остальном же, к примеру, характер организации производства, может быть практически полностью скопирован с учётом культурных особенностей (если применимо). Поставщики также относятся ко второй категории, хоть и очевидно, что их метод работы с сырьем отличается, но и здесь возможно транслирование применимых подходов, опять же, с учетом особенностей производства, культурного фактора (если применимо), особенностей законодательства.

Что касается третьей категории - необходимо сравнение методов организации работ по ключевым параметрам: объем и длительность цикла производства, требования, рыночная ситуация (высоко ли ценовое давление издержек), культурные особенности (если предприятия функционируют в разных культурах) и метод организации производственного проекта в рамках предприятия.

Наибольший эффект может дать использование бенчмаркинга для управления инновационными проектами. Действительно, разработаны типовые инструменты планирования и управления проектами, которые позволяют формализовать процессы проектов для снижения рисков. При этом использование адаптированных инструментов, успешно зарекомендовавших себя при реализации похожих проектов, является оправданным и позволяет повысить эффективность управления.

Как показывает практика, принятые по умолчанию и функционирующие инструменты управления проектом в сфере сборки автомобилей могут быть применены для программ по выпуску авиакомпонентов. Существенно то, что внедрение проектного подхода к управлению программами по выпуску авиакомпонентов придает финансовой эффективности, свойственной проектам предприятия-партнера по бенчмаркингу, потому что в случае ее отсутствия, проект либо не рассматривается как возможный для исполнения, либо, в случае стратегической значимости проекта, создается план по достижению такой эффективности. Управление проектом как подход позволяет эффективно достигать целей этого плана. Инструменты, используемые в управлении финансами проекта, формулировки требований к проекту, управления по целям и управления рисками в проекте являются наиболее важными в рассматриваемом контексте.

Действительно, одним из важных этапов управления проектом является управление финансами. В общем случае задачами управления финансами проекта являются (Хофман, 2006):

- Экономичность.

- Стратегическая направленность.

- Обеспечение непрерывной реализации проекта.

- Выполнение законных обязательств собственника проекта (например, относительно окружающей среды, безопасности).

Важно отслеживать непротиворечивость управления, то есть недопустима экономия за счет снижения уровня качества проекта.

Формализация проекта с точки зрения финансов предполагает:

- Четкое описание проекта (содержание, разграничение по времени).

- Определение обязанностей и сочетаний (основание для распределения бюджета).

- Перечисление пакетов работ и их отнесение к ответственному по финансам.

- Оценку использования ресурсов.

- Указание дополнительных затрат (текущие расходы серийного производства).

- Представление потоков платежей.

- Анализ затрат и эффективности.

- Оценку экономики проекта (рентабельность, амортизация, совокупный капитал).

- Гарантии финансирования (прямое финансирование через клиента, предоставление краткосрочных кредитов, покрытие бюджета).

- Предложение по проекту и утверждение. 
Из перечисленного выше многое уже применяется в проектах производственных предприятий авиастроения, однако такие составляющие, как четкое описание проекта (или программы в случае серийной стадии изготовления), анализ затрат и эффективности, оценка экономичности и гарантия финансирования с обоснованной частью по управлению изменениями в проекте, стоит рассмотреть для внедрения в первую очередь. Описание проекта дает четкое представление о том, что это за проект, каков его масштаб, суть, кто руководитель и каковы основные цели. Важна формализация этого документа, поскольку лишь согласованная версия формирует единое понимание у всех заинтересованных сторон. Далее, анализ затрат и экономика - составляющая, которая дает прозрачность и понимание затратной части проекта. Оценка экономики позволяет понять, когда проект выйдет на самоокупаемость. Так становится понятным, когда проект «планово нерентабелен», а когда его нерентабельность стала постоянным, т.е. неуправляемым, показателем. И наконец, гарантии финансирования, особенно важные в случае высокозатратных проектов и сказываются на ходе проекта и его результатах. Частью гарантий финансирования являются гарантии финансирования в случае изменений. Ясно, что важным аспектом контракта является внесение изменений в изделие, это влияет на процесс реализации проекта, поскольку процесс создания авиатехники сложен, проходит в несколько этапов и цена изменений высока, особенно если изменение вносится на стадии завершения изготовления продукта. Таким образом, изменение, внесенное с опозданием, инициирует огромные затраты, поэтому ответственность, в том числе и финансовую, за проведение таких изменений необходимо четко формализовать в контракте. То есть для планирования потоков платежей может быть заимствована процедура составления и заключения контрактов. Поскольку рынок поставщиков ограничен, знание условий работы с данным поставщиком другого контрагента, специфика ценообразования, процедур согласования (в том числе принципиальных аспектов, по которым могут возникнуть расхождения) может как снизить затраты на проект, так и ускорить процесс заключения контракта.

Следующим принципиально важным объектом для бенчмаркинга является оценка рисков. Так как самолетостроение - это штучное производство, статистики по возможным рискам проекта в рамках одного предприятия не существует. Следовательно, заложить данные риски в бюджет проекта превентивно не представляется возможным. Бенчмаркинг рисков как таковых достаточно проблематично провести, поскольку риски уникальны для проекта и среды его реализации. Однако бенчмаркинг может быть полезен при выборе инструмента для общей проверки наличия рисков. В этом случае появляется возможность сформулировать риски и потом по каждому из них проработать сценарии реакции, чтобы минимизировать влияние рисков в процессе работы по контракту. В общем случае цель управления рисками в проекте - распознание и оценка потенциальных рисков, и, при необходимости, ввод мероприятий по их снижению (Хофман, 2006).

Для проверки всевозможных рисков в проектах предприятия-донора применяется следующая форма (см. таблицу 2), ее рекомендуется использовать для проверки рисков проекта.

Таблица 2

Лист проверки рисков проекта

\begin{tabular}{|c|c|c|}
\hline Тип рисков & $\begin{array}{l}\text { Название } \\
\end{array}$ & $\mathrm{V}$ \\
\hline \multirow{5}{*}{$\begin{array}{l}\text { 1. Влияние на } \\
\text { бизнес и } \\
\text { преимущества } \\
\text { реализации } \\
\text { проекта }\end{array}$} & Стратегическое воздействие & \\
\hline & Широкая поддержка & \\
\hline & Качественный скачок & \\
\hline & Уровень уверенности & \\
\hline & Ожидаемые издержки/выгоды & \\
\hline \multirow[t]{3}{*}{ 2. Размер проекта } & Бюджет & \\
\hline & Определены ли исходные данные & \\
\hline & Временные ограничения и другие ресурсы & \\
\hline
\end{tabular}




\begin{tabular}{|c|c|}
\hline 3. Организационное & На что оказывает влияния? Какое? Различные группы? \\
\hline влияние & Географическое покрытие и месторасположение \\
\hline & Уровень изменения культуры \\
\hline & Легитимность изменений \\
\hline & Уровень сопротивления \\
\hline & Уровень вовлеченности руководства \\
\hline & Изменения в работах, навыках, отношениях, власти \\
\hline & Проигрывающие или выигрывающие \\
\hline & Уровень коммуникационной подготовленности \\
\hline 4. Технические & Уровень опыта во внедряемых технологиях? \\
\hline риски и & Релевантность по отношению к целям, надежности, \\
\hline сложность & Цепная реакция \\
\hline & Надежность поставщиков - техническая/коммерческая \\
\hline & Природа взаимоотношений \\
\hline & Взаимосвязи - особенно критические \\
\hline 5. Управление & Резюме и ожидания \\
\hline проектом & Спонсорская поддержка \\
\hline & Процесс принятия решений в организации \\
\hline & Принятия решений в проекте \\
\hline & Подходящие методы и процессы для определения выходных \\
\hline & Жизненный цикл проекта \\
\hline & Планирование управленческих работ \\
\hline & Ресурсы \\
\hline & Обратная связь и прямая \\
\hline & Управление всеми заинтересованными лицами проекта \\
\hline
\end{tabular}

Таблица задает типы рисков для их проработки, перечисляя все возможные из них в рамках каждого типа. Первый тип связан с влиянием проекта на основной бизнес организации и рассматривает преимущества, которые дает реализация проекта. Второй тип связан с масштабом проекта, третий - с влиянием проекта на организационную составляющую предприятия, четвертый тип связан непосредственно с техническими сложностями в ходе реализации проекта, и пятый тип связан непосредственно с руководством проектом. Итак, в части рисков бенчмаркинг может лишь быть механизмом, дающим основу для их формулировки и анализа, но никак не определяющим их.

Таким образом, можно сделать вывод, что при помощи бенчмаркинга возможно инсталлировать ряд инструментов, повышающих финансовую эффективность проекта. В теории финансового менеджмента существует следующее определение: «расходование ресурсов в надежде на получение доходов в будущем, по истечении достаточно длительного периода времени» (Бирман, Шмидт, с. 13). Определение дано применительно к инвестиции, однако в ракурсе бенчмаркинга также применимо, поскольку и бенчмаркинг чаще всего подразумевает расходование, будь то финансирование работы консультантов или же собственного персонала, работающего в проекте по бенчмаркингу, а эффект от такой работы зачастую можно увидеть не сразу, особенно в рассматриваемой отрасли, поскольку подвергаемые бенчмаркингу инструменты нужно получить, изучить, протестировать, внедрить и только потом получить первый эффект от внедрения; однако наиболее корректно оценивать эффект после внедрения инструмента во всех проектах предприятия, где инструмент может быть применим. Также, не забывая о кривой обучения, стоит учитывать повышение эффективности использования инструмента по мере его освоения.

Итак, отнесем бенчмаркинг к инвестициям, причем реальным, поскольку бенчмаркинг чаще связан с проектно-изыскательскими работами. Соответственно, критерии оценки инвестиционных проектов можно использовать и для оценки эффективности проектов бенчмаркинга в разные периоды времени по отношению к проекту. Такие расчетные 
показатели, как NPV (net present value - чистая дисконтированная стоимость), - при необходимости сравнить общие инвестиции в бенчмаркинг и чистые денежные потоки от его реализации в начале проекта (сложность будет в точности оценки прогнозируемых потоков); NTV (net terminal value - чистая терминальная стоимость) - при оценке бенчмаркинга в прошлом, насколько этот проект в итоге оказался эффективным для организации; PI (profitability index - индекс рентабельность инвестиции), показывающий уровень дохода на единицу затрат, и DPP (discounted payback period - дисконтированный срок окупаемости инвестиций), показывающий срок окупаемости инвестиций, будут корректны, поскольку учитывают временной фактор, столь важный в случае бенчмаркинга.

\section{Список литературы}

1. Бирман Г., Шмидт С. Экономический анализ инвестиционных проектов / пер. с англ.: под ред. Л.П. Белых. М: Банки и Биржи, ЮНИТИ, 1997.

2. Ципес Г.Л., Товб А.С. Менеджмент проектов в практике современной компании. М.: ЗАО «Олимп-бизнес». - 304 с.

3. Хофман И.М. G10104 Управление проектом MSPM - Управление проектом MAGNA STEYR // Групповой стандарт компании Magna Steyr. URL: http://www.magna.com.

4. Deresky, H. \& Christopher, E. (2008), International management: managing across boarders and cultures. Sydney: Pearson Education 